\title{
Effect of e-cigarette flavoring agents on the neural retina of chick embryo: histological and gene expression study
}

\author{
Malak Alshareef $^{1}{ }^{\circledR}$, Aziza Alrafiah ${ }^{2 *}$, Sara Abed ${ }^{1}$, Fatemah Basingab ${ }^{1}$, Aisha Alrofaidi1 \\ ${ }^{1}$ Biological Sciences Department, Faculty of Science, King Abdulaziz University, Jeddah, \\ Saudi Arabia \\ ${ }^{2}$ Department of Medical Laboratory Technology, Faculty of Applied Medical Sciences, \\ King Abdulaziz University, Jeddah 21589, Saudi Arabia
}

\begin{abstract}
Background. An electronic cigarette (e-cigarette) is initially marketed as an assistant product to quit smoking or limit its use. However, recent studies suggest the opposite, describing it as a product that lacks adequate quality and user safety. The present study aimed to investigate the effect of e-cigarette flavoring agent (cinnamon flavor) on the neural retina development of chick embryos and apoptosis induction after the early and late apoptosis stages by quantitative detection of gene expression CASP-3 at both embryonic days E9 and E17.

Methods. Fertilized chicken eggs were divided into two groups: control and treatment, and each group included two embryonic days; E9 and E17. For each treatment stage, two dosages of the treatment were applied, $2 \%$ and 5\%. The neural retinas were dissected from the sclera and retinal pigment epithelium for subsequent RNA extraction and histological examination.

Results. This study indicated that aerosol of the subtle cinnamon flavor e-liquid causes downregulated expression of CASP3 in neural retina development. In addition, the hematoxylin and eosin (H\&E)-stained sections showed multiple structural changes in the retinal layers and evidence of apoptotic cell death.

Conclusion. Cell death was visible and abundant in E9, and E17 concludes that flavor vapor condensate treatment caused neuronal cell death. CASP-3 was downregulated, which indicates that cell death occurred independently of CASP-3. (Folia Histochemica et Cytobiologica 2021, Vol. 59, No. 4, 245-258)
\end{abstract}

Key words: chick embryo; caspase-3 (CASP-3); electronic cigarette; histology; retinal development

\section{Introduction}

Electronic cigarettes (e-cigarettes), also known as electronic nicotine-delivery systems, are hand-held products that mimic the use of traditional cigarettes but do not burn $[1,2]$. Flavoring agents are optional

Correspondence address: Aziza Alrafiah

Department of Medical Laboratory Technology,

Faculty of Applied Medical Sciences,

King Abdulaziz University, Jeddah 21589, Saudi Arabia

phone: +966-0126401000 (ext. 23495)

e-mail: aalrafiah@kau.edu.sa components of e-cigarette liquids, including traditional flavors, such as tobacco or menthol, and contemporary flavors like fruit, sweet, and beverage. Besides, many e-cigarette users may create a mixture of different flavors available through manufacturers of nutritional flavors to create exclusive flavors [3, 4]. The addition of flavoring agents in e-liquid has led to increased e-cigarette product marketing and allowed the manufacturers of e-liquid to market these liquids with attractive names amongst consumers, especially young people $[5,6]$. More than $75 \%$ of e-cigarette users prefer to use other flavors than tobacco. The two most common flavors among e-cigarette users are fruit and sweet. In addition, cinnamon flavor e-liquids

This article is available in open access under Creative Common Attribution-Non-Commercial-No Derivatives 4.0 International (CC BY-NC-ND 4.0) license, allowing to download articles and share them with others as long as they credit the authors and the publisher, but without permission to change them in any way or use them commercially. 
(cinnamaldehyde) are often identified as best sellers [7]. However, the Flavor Extract Manufacturers Association (FEMA) has indicated that they must be used at specific concentrations only in consumed foods, not through exposure to heating using e-cigarettes and inhalation [5].

One previous study indicated that the free-nicotine e-liquids cause cytotoxicity to different cells in vitro [8]. The cytotoxicity of 41 e-liquids was evaluated on mouse neural stem cells, human embryonic stem cells, and human pulmonary fibroblasts. The cytotoxicity was related to the number and concentrations of chemicals used in the flavors and not exposure to nicotine. The cinnamon flavor was the most potent effect on the three types of cells [7]. Previous studies indicated that e-liquid aerosol inhalation leads to DNA damage, carcinogenesis, inflammation, oxidative stress, and apoptosis [9]. Also, a previous study found that levels of reactive free radicals in e-cigarette vapors are high, reaching greater than 1013 molecules per puff, and may contribute to the development of smoking-related diseases [10]. e-Cigarettes may not be an effective alternative for quitting smoking, due to the lack of monitoring and laws that include sufficient quality and safety for the user $[11,12]$.

Caspase-3 (CASP-3) is an executioner caspase because it causes cellular dysfunction and destruction of cellular structures such as DNA fragmentation and leads to cell shrinkage. Numerous research studies focused on apoptosis in the developing nervous system $[13,14]$. CASP-3 is associated with numerous acute and chronic neurodegenerative disorders, including Huntington's disease, Alzheimer's disease, and Parkinson's disease, distinguished by neuronal cell death [13]. Although CASP-3 has been recognized as a significant factor in the occurrence of apoptosis, there are molecular mechanisms involved in regulating apoptosis independent of caspase that are somewhat unknown [15]. Also, apoptosis may occur in response to oxidative stress [16]. Smoking, in general, contributes to the development of many diseases. This may be due to the oxidative stress induced by free radicals, which influence many cellular pathways. One previous study showed an increase in the free radical production in the e-cigarette aerosols containing flavors compared to the e-cigarette aerosols free of nicotine and flavor [17, 10]. Exposure to e-cigarette vapor has been observed to increase oxidative stress levels, impair gene expression and molecular pathways, and cause DNA damage [8]. Previous studies have shown that increased oxidative stress on the retina causes diseases in the retina, such as retinal degeneration or other types of neurodegenerative disorders. In comparison, the oxygen supply in the retina decreases, even though the blood supply is still normal, which causes an excessive oxidation state that affects all cells and therefore subjects them to apoptosis [18].

The chicken (taxon - Gallus gallus) was one of the first models for developmental research and one of the best models for studying many eye diseases, especially the retina. This enables researchers to conduct several experiments in a short period and collect a large amount of data. The anatomical structure of the chicken eye indicates that it contains the same essential components of the human eye: cornea, sclera, choroid, ciliary body, lens, iris, retina, optic nerve, but with differences, including chicken eyes are oblate, with an axial length of $12-13 \mathrm{~mm}$ [19]. Previous studies have shown that neurons in the chicken retina are produced excessively. During development, two cell death waves occur in the developing nervous system in which half or more of these cells are eliminated afterward. In the chick embryo retina, the first wave occurs between embryonic day (E4) and E7, and the second wave occurs between embryonic day (E10) and E14. Between them, the regulation level of apoptosis generally decreases [20].

The present study aimed to investigate the effect of e-cigarette flavoring agents (cinnamon flavor) on the neural retina development of chick embryos and in inducing apoptosis after the early and late apoptosis stages in the neural retina of chick embryos by qualitative detection of gene expression of CASP-3 with RT-qPCR at both E9 and E17. Furthermore, the study examined the morphological changes in the retinal tissue in response to the treatment with e-cigarette vapor condensate at the same embryonic stages.

\section{Materials and methods}

Ethics statement. The study was ethically reviewed by King Fahd Medical Research Center, King Abdulaziz University, Jeddah, Saudi Arabia. The experimental protocol was approved by the Animals Care and Use Committee (ACUC) and Research Ethics Committee (REC).

Materials. e-Cigarette third-generation device was purchased as a kit (SMOK, Shenzhen IVPS Technology Co Limited, Shenzhen, China). e-Liquid components were purchased from an international commercial online shop and were prepared manually in the laboratory. Pipet tip (Super-silk, Labcon. Petaluma, CA, USA), Masterflex Platinum-cured Silicone tubing $2.06 \mathrm{~mm}$ (Cole-Parmer, Vernon Hills, IL, USA), centrifuge tube (Eppendorf Corporate, Hamburg, Germany), and parafilm (Bemis Company, Inc, Oshkosh, WI, USA). Sterile syringes were purchased from BD Micro-Fine ${ }^{\mathrm{TM}}$ Plus, USA. RNAlater ${ }^{\circledR}$ solution, RNeasy Mini Kit, and QuantiFast SYBR ${ }^{\circledR}$ Green PCR Kit were purchased from QIAGEN, Hilden, Germany, and Nano 
Drop 2000C (Thermo Scientific, Waltham, MA, USA), ImProm-II ${ }^{\mathrm{TM}}$ Reverse Transcription System kit (Promega ${ }^{\mathrm{rm}}$, Corporation, Madison, WI, USA).

Animals. Fertilized chicken eggs were obtained from a local farm in Jeddah, Saudi Arabia, and incubated in humidified incubators at $38.2^{\circ} \mathrm{C}$ with rotation every 6 hours (Black Chick incubators, Bangkok, Thailand) for the specified embryonic days according to Hamburger and Hamilton staging system.

Study design. Eggs were divided into two groups: control group and treatment group and each group include two embryonic days; E9 and E17. For each treatment stage, two dosages of the treatment were applied, low $(2 \% \mathrm{v} / \mathrm{v})$ and a high $(5 \% \mathrm{v} / \mathrm{v})$ concentration. Flavoring agent (e-liquid) was prepared according to $\mathrm{v} / \mathrm{v}$ percentage in $10 \times$ phosphate-buffered saline (PBS).

Preparation of e-cigarette aerosols condensate. The steam engine website's publicly available calculating tool (https:// www.steam-engine.org/) was used to prepare the components at a given percentage concentration.

In an empty and dark bottle, the mixture of PG/VG was prepared at a ratio of 50/50 and contained flavoring liquid at $15 \%$. Then the mixture was stored in a dark and cool place for three weeks to allow its components to bind together. The e-cigarette was set at $55 \mathrm{~W}$ and 70 volts per puff. Puff is set to act as a simulation of human use. Puff duration was for 5 seconds with intervals of 30 seconds. While running the e-cigarette, the mouthpiece of the e-cigarette was connected to a collection system introduced by Olmedo et al. [21], containing a series of $200 \mu \mathrm{l}$ pipet tips alternating with Masterflex Platinum-cured Silicone tubing $2.06 \mathrm{~mm}$. In this study, a small water pump appliance was used to generate the e-cigarette aerosol. The puffed e-cigarette aerosol condenses at room temperature as it flows through the system then collected in a $1.5 \mathrm{ml}$ centrifuge tube and sealed by parafilm. Then the condensate was diluted immediately to the desired concentration with $10 \times$ PBS.

Treatment. At E7, the eggs were first sterilized, then a hole was made in the air chamber with a needle tip to treat the embryos by injecting the treatment solution using sterile syringes. $0.1 \mathrm{ml}$ of e-cigarette aerosols condensate was injected for all samples. Finally, the injected spot was sealed with transparent tape.

Dissection. The eggs were opened from the air chamber at the desired embryonic stages, E9 and E17, and embryos were extracted and placed into a Petri dish in a $10 \%$ PBS physiological solution. Embryos were immediately decapitated with scissors, and eyelids were cut away to remove the left whole eye without piercing it carefully. The front of the eye is removed, along with the vitreous body using forceps. Then, the neural retinas were dissected from the sclera and retinal pigment epithelium, transferred to RNAlater ${ }^{\circledR}$ solu- tion, and stored at $4^{\circ} \mathrm{C}$ for subsequent total RNA extraction. The whole right eye was used for histological examination.

Gene expression. RNeasy Mini Kit performed total RNA extraction for retina tissue. RNA purity and concentration were assessed by determining the spectrophotometric absorbance of the samples at 230, 260, and $280 \mathrm{~nm}$ and ratios of A260:A280, total RNA extraction was stored at $-80^{\circ} \mathrm{C}$. Complementary DNA (cDNA) synthesis selectively from mRNA by utilizing ImProm-II ${ }^{\mathrm{TM}}$ Reverse Transcription System kit was synthesized. Complementary DNA (cDNA) synthesis selectively from mRNA by utilizing ImProm-II ${ }^{\mathrm{TM}}$ Reverse Transcription System kit was synthesized. Custom-made primers were designed for CASP-3 and beta-Actin housekeeping gene ( $\beta A C T$.) using the web-based program Primer3Plus (http://www.bioinformatics.nl/primer3plus).

The sequence of primers that used in experiment $C A S P 3$ (GeneBank ID: NM_204725.1) Forward 5' AGC GAA GCA GTT TTG TTT GT 3' and Reverse 5' GGT CCA CTG TCT GCT TCA AT 3'. $\beta A C T$ (GeneBank ID: NM 205518.1) Forward 5' TGG AGT CCT GTG GTA TCC AT 3' and Reverse 5' GCT GTG ATC TCC TTC TGC AT 3'. RT-qP$\mathrm{CR}$ reaction was performed by using standard protocols, QuantiFast SYBR ${ }^{\circledR}$ Green PCR Kit. A mixer of a total $20 \mu \mathrm{l}$ was prepared by a combination of cDNA and nuclease-free water according to the cDNA concentration. Finally, PCR Master Mix was prepared for $C A S P 3$ and $\beta A C T$.

Histological studies. For light microscopy, the whole right eyeball from each embryo was immersed in $10 \%$ neutral-buffered formalin for 24 hours, washed, dehydrated, cleared, and then embedded in paraffin. Paraffin sections of 5-7 $\mu \mathrm{m}$ thickness, mounted on glass slides for hematoxylin and eosin (H\&E) [22] staining to examine the histological changes in the different groups. Slides were examined and taken images using Olympus BX51 microscope (Tokyo, Japan) at $20 \times$, and $40 \times$ magnification power.

Statistical analysis. Calculations were performed for relative gene expression fold change by delta-delta $C_{T}\left(\Delta \Delta C_{T}\right)$ method using MS Excel. Data were expressed as mean $+/-$ standard error of cycle threshold $\left(\mathrm{C}_{\mathrm{T}}\right)$ data mean and were analyzed by IBM SPSS Statistics for Windows, version 23 (IBM SPSS, IBM Corp., Armonk, NY, USA) for comparative analysis between pairs of groups using ANOVA with a post-hoc test. $\mathrm{C}_{\mathrm{T}}$ replication values were used for the comparative test. $p<0.05$ is considered statistically significant.

\section{Results}

\section{Viability analysis}

When observing the vitality of the injected embryos and comparing them with the control, it was observed that all samples were alive when opened at E9 and E17 and no congenital malformations were observed (Fig. 1 and Fig. 2). 

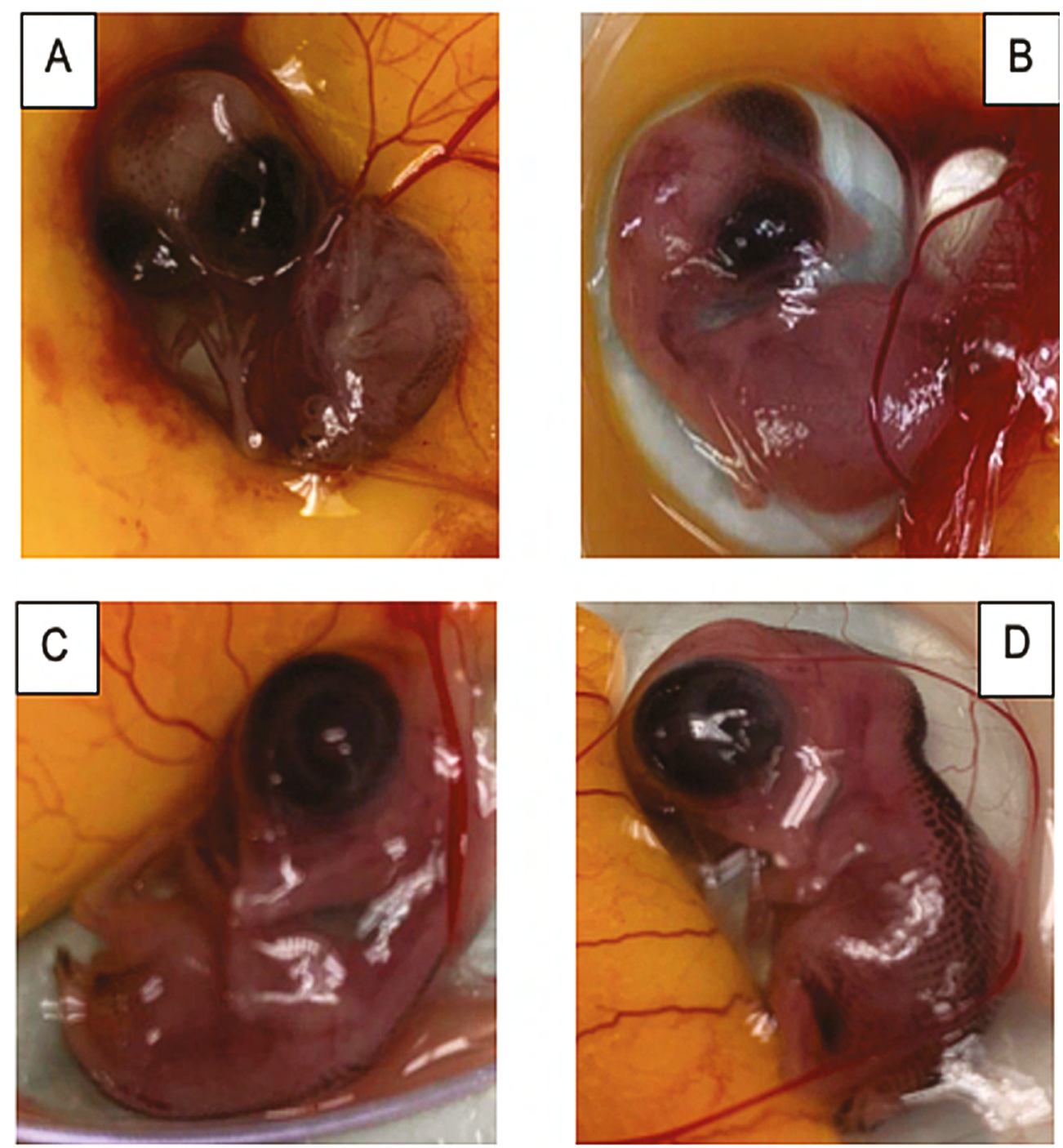

Figure 1. Chick embryo at E9 was injected with e-cigarette aerosol condensate containing cinnamon flavor at the low concentration of $2 \%(\mathbf{A}, \mathbf{B})$ and at high concentration of $5 \%(\mathbf{C}, \mathbf{D})$.

Table 1. CASP-3 expression fold change at E9

\begin{tabular}{|l|c|c|c|c|c|c|}
\hline \multirow{2}{*}{ Sample ID } & \multirow{2}{*}{ Avg. Cт CASP-3 } & \multirow{2}{*}{ Avg. CT $\beta$ ACT } & \multicolumn{3}{|c|}{ Reference PBS } \\
\cline { 4 - 7 } & & & $\Delta \mathbf{C}$ T & $\Delta \Delta \mathbf{C}$ T & Ratio & $\begin{array}{c}\text { Downregulation fold } \\
\text { change (1/R) }\end{array}$ \\
\hline E9 WT control negative & $5.653 \pm 0.2$ & $7.154 \pm 2.9$ & -1.501 & -0.727 & 1.655 & \\
\hline E9 Low concentration & $21.734 \pm 3$ & $14.773 \pm 6.8$ & 6.961 & 7.735 & 0.005 & 213 \\
\hline E9 High concentration & $29.042 \pm 8.6$ & $15.425 \pm 2.6$ & 13.617 & 14.391 & 0.00005 & 21480 \\
\hline
\end{tabular}

Data were expressed as mean \pm standard error. WT — wild type; PBS — phosphate-buffered saline; $(\Delta \Delta \mathrm{CT})$ — delta-delta CT; (CT) — cycle threshold

\section{The real-time reverse transcription-quantitative} polymerase chain reaction (RT-qPCR) results

CASP-3 gene expression analysis revealed that both treatment concentrations had an effect. At E9, CASP3 expression level was significantly higher in group I control wild type and group II control PBS versus E9 samples treated. The results indicated that CASP-3 in group III low concentration $2 \%$ was significantly downregulated (213-fold change), and observable downregulation for group IV high concentration 5\% (21480-fold change) (Table 1 and Fig. 3). Meanwhile, at E17, the CASP-3 expression level in the control PBS 

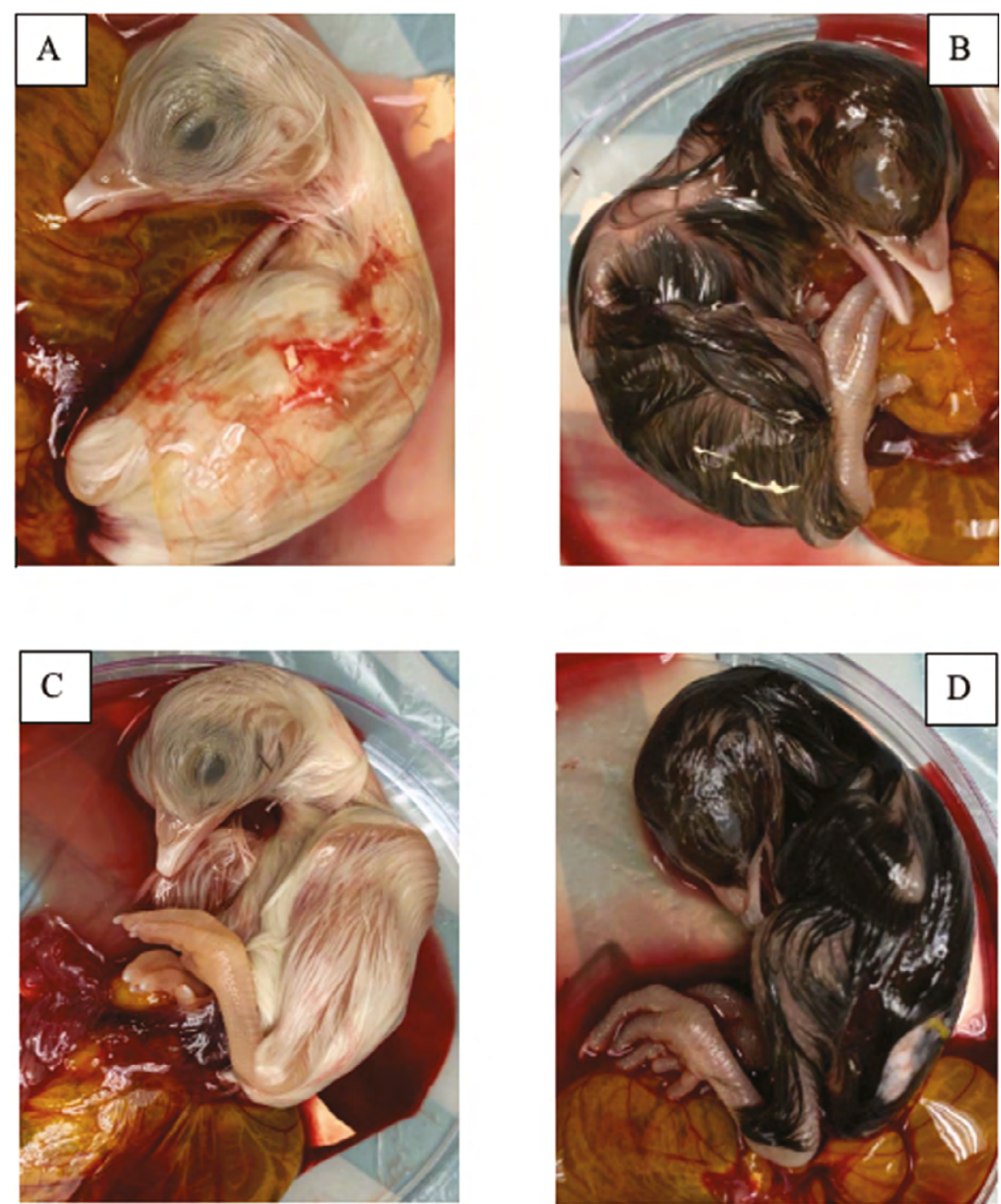

Figure 2. Chick embryo at E17 was injected with e-cigarette aerosol condensate containing cinnamon flavor at low concentration $2 \%(\mathbf{A}, \mathbf{B})$ and at high concentration $5 \%(\mathbf{C}, \mathbf{D})$.

Table 2. CASP-3 expression fold change at E17

\begin{tabular}{|l|c|c|c|c|c|c|}
\hline Sample ID & Avg. Cт $\mathbf{C A S P - 3}$ & \multirow{2}{*}{ Avg. Ст $\beta \boldsymbol{A C T}$} & \multicolumn{3}{|c|}{ Reference PBS } \\
\cline { 4 - 7 } & & & $\Delta \mathbf{C T}$ & $\Delta \Delta \mathbf{C T}$ & Ratio & $\begin{array}{c}\text { Downregulation fold } \\
\text { change (1/R) }\end{array}$ \\
\hline E17 WT control negative & $35.070 \pm 1.5$ & $28.626 \pm 1.5$ & 6.344 & 13.482 & 0.00009 & 11437 \\
\hline E17 Low concentration & $32.661 \pm 5.2$ & $25.342 \pm 4.6$ & 7.320 & 14.457 & 0.0004 & 22490 \\
\hline E17 High concentration & $31.687 \pm 1.8$ & $30.910 \pm 2.1$ & 0.777 & 7.914 & 0.004 & 241 \\
\hline
\end{tabular}

Data were expressed as mean \pm standard error. WT — wild type; PBS — phosphate-buffered saline; $(\Delta \Delta \mathrm{CT})$ — delta-delta Cт; $\left(\mathrm{CT}_{\mathrm{T}}\right)$ — cycle threshold

group was significantly higher than the other three groups. CASP-3 in E17 was significantly downregulated in samples group I control wild type (11437-fold change), observable downregulation in group III low concentration of $2 \%$ (22490-fold change), and downregulation for group IV high concentration 5\% (241-fold change) (Table 2 and Fig. 4).

At E9, CASP3 expression level was significantly different in low dose $(p=0.005$ and $p=0.003)$ and high dose $(p=0.001$ and $p=0.001)$ versus WT and 


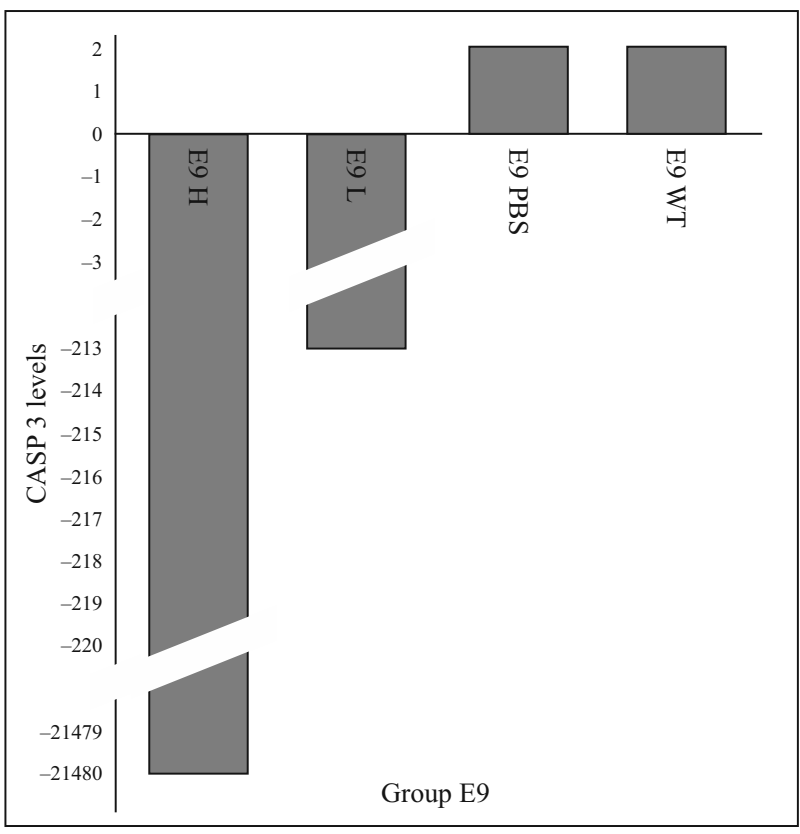

Figure 3. CASP-3 downregulation pattern in the neural retina at E9 in response to treatment with high $(\mathrm{H})$ or low $(\mathrm{L})$ concentrations of e-cigarette aerosol condensate containing cinnamon flavor compared with controls wild type and PBS.

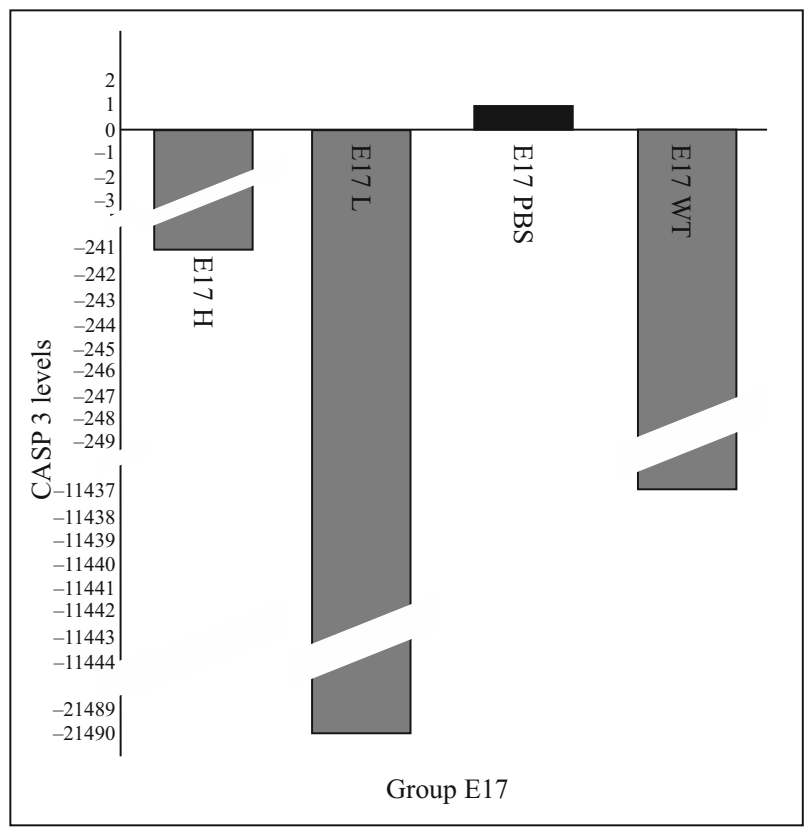

Figure 4. CASP-3 downregulation pattern in the neural retina at E17 in response to treatment with high $(\mathrm{H})$ or low $(\mathrm{L})$ concentrations of e-cigarette aerosol condensate containing cinnamon flavor and CASP-3 downregulation pattern in control wild type compared with control PBS.

PBS, respectively. Meanwhile, at E17, CASP3 expression level in PBS group was significantly different than WT $(p=0.006)$, low dose $(p=0.026)$ and high dose $(\mathrm{p}=0.015)$. In WT group, CAPS3 was significantly higher in E17 versus E9 $(p<0.0001)$ (Table 3 and Fig. 5).

\section{Histological Studies}

Histological studies at E9

Chick embryo group I (control wild type) (Figs. 6A and 7A) and Group II (control PBS) (Figs. 6B and 7B) showed the same histological findings of the retinal layers in H\&E-stained sections. It was formed of retinal pigment epithelium (RPE), photoreceptor layer (PRL) of rods and cones, outer limiting membrane (OLM) outer nuclear layer (ONL), outer plexiform layer (OPL), inner nuclear layer (INL), inner plexiform layer (IPL), ganglion cell layer (GCL), nerve fiber layer (NFL), and the inner limiting membrane (ILM). The outermost RPE was a single layer of small cuboidal cells with pale, oval, basal nuclei and filled with pigment granules. This layer was resting on Bruch's membrane, which separated it from the choroid. The sclera showed two layers, an inner cartilaginous layer, and an outer fibrous layer. The fibrous layer was thinner than the underlying cartilaginous layer and consisted of closely packed collagen fibers and hyaline cartilage with chondrocytes surrounded by the matrix. The rods and cones were a small, pale region located between ONL and RPE. The photoreceptor layer showed an eosinophilic parallel fibrillary striation pattern and was composed of lightly stained outer segments and deeply stained inner segments of the rods and cones. The thick ONL was formed of several rows containing the closely packed densely stained nuclei of rods and cones' cell bodies. The nuclei were predominantly oval, and few appeared with elongated nuclei. The identification of this layer depended on the presence of the OPL which appeared as a loose network of eosinophilic fibers. The INL formed of numerous, relatively larger cells and their nuclei were paler than those of the outer nuclear one. The GCL was composed of a single discontinuous row of the cell bodies of the ganglion cells. The ganglion cells appeared as pear-shaped cells with a large round nucleus. The axons of the GCL were forming the NFL. The ILM appeared as a thin membrane.

Group III (low concentration 2\%) showed separation of the retinal pigmented epithelium with disorganization and vacuolated retinal pigment epithelium in the RPL. A few vacuolations in the outer segment of the PRL. OPL appeared thinned and disrupted. Multiple empty spaces are noticed in the INL as well as an apparent decrease in the thickness of the ONL with disorganized cells. Scleral cartilage cell nests appeared with many apoptotic nuclei. The GCL was observed in focal areas with multiple vacuolation 
Table 3. Comparison of the levels of CASP-3 in different studied groups on different days

\begin{tabular}{|l|c|c|c|}
\hline \multicolumn{1}{|c|}{ Days } & E9 & E17 & Significance \\
\hline WT & $5.65 \pm 0.14$ & $35.07 \pm 0.86$ & $\boldsymbol{P}<\mathbf{0 . 0 0 0 1}$ \\
\hline PBS & $5.57 \pm 1.00$ & $18.82 \pm 4.88$ & $p=0.072$ \\
\hline Significance & ${ }^{1} p=0.984$ & ${ }^{1} \boldsymbol{p}=\mathbf{0 . 0 0 6}$ & $p=0.053$ \\
\hline Low dose & $21.73 \pm 1.72$ & $32.66 \pm 3.66$ & \\
\hline Significance & ${ }^{1} \boldsymbol{p}=\mathbf{0 . 0 0 5} ;{ }^{2} \boldsymbol{p}=\mathbf{0 . 0 0 3}$ & ${ }^{1} p=0.672 ;{ }^{2} \boldsymbol{p}=\mathbf{0 . 0 2 6}$ & $p=0.542$ \\
\hline High dose & $29.04 \pm 6.10$ & $31.69 \pm 0.91$ & \\
\hline Significance & ${ }^{1} \boldsymbol{p}=\mathbf{0 . 0 0 1} ;{ }^{2} \boldsymbol{p}=\mathbf{0 . 0 0 1} ;{ }^{3} \mathrm{p}=0.095$ & ${ }^{1} \mathrm{p}=0.481 ;{ }^{2} \boldsymbol{p}=\mathbf{0 . 0 1 5} ;{ }^{3} \mathrm{p}=0.856$ & \\
\hline
\end{tabular}

Data were expressed as mean \pm standard error. ${ }^{1} p-$ significance versus $\mathrm{WT} ;{ }^{2} p-$ significance versus $\mathrm{PBS} ;{ }^{3} p-$ significance versus low dose; $p$ - significance versus the same group in different ages.

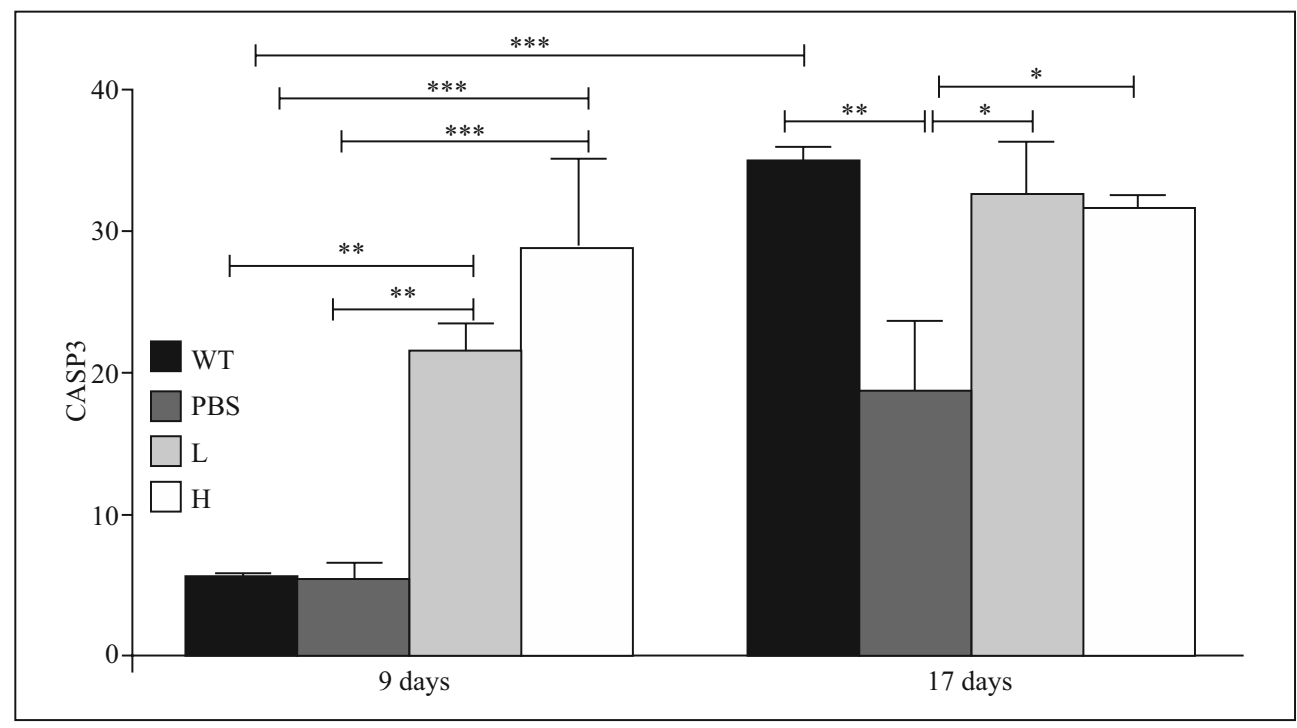

Figure 5. Comparison of the levels of CASP-3 in different studied groups at different days. Data were expressed as mean \pm standard error. ${ }^{*} \mathrm{p}<0.05 ; * * \mathrm{p}<0.01 ; * * * \mathrm{p}<0.001$.

areas around a few shrunken irregular ganglion cells and some cells had deeply stained nuclei pyknotic nuclei (Figs. 6C and 7C).

$\mathrm{H} \&$ E-stained sections of chick embryo (group IV) treated with high concentrations of $5 \%$ showed marked multifocal structural changes. The retinal pigmented epithelium's detachment appeared in focal areas, and in most of the retinal pigment epithelium revealed deeply stained acidophilic cytoplasm with deeply stained pyknotic nuclei. The PRL showed disorganization with multiple vacuolations areas in the outer segments. Some photoreceptor nuclei appeared pyknotic in the ONL. Moreover, the diminished cell population of the ONL and INL was noticed with empty spaces between their cells. Many cells in the INL showed dark pyknotic nuclei. Moreover, there was disorganization of the OPL and IPL with widening of the spaces between their fibers mostly appeared in the IPL. The GCL showed rarefaction or vacuolation and contained disorganized cells with deeply stained pyknotic nuclei. Scleral cartilage appeared with dark pyknotic nuclei (Figs. 6D and 7D).

\section{Histological studies at E17}

Group I control wild type (Figs. 8A and 9A) and group II (control PBS) (Figs. 8B and 9B) exhibited the same histological findings. They showed all layers of the retina. The sections were at a more advanced stage than E9 embryo development. In this age group, the retinal layer was clearly defined. In histological sections in E17 embryos, the sclera from the wild control group showed hyaline cartilage in the scleral layer. 

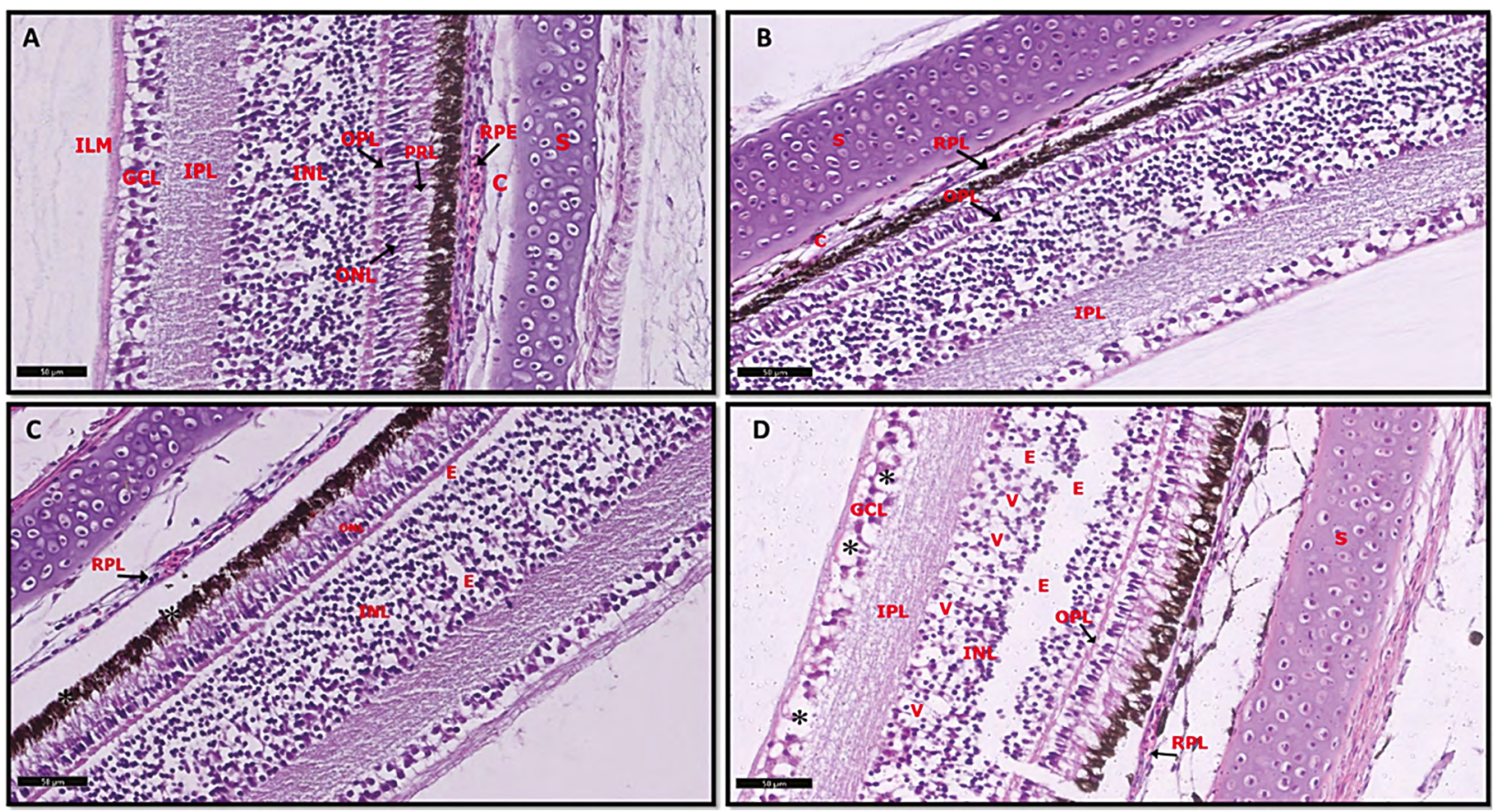

Figure 6. Photomicrographs of a section in the retina of at E9 at magnification $20 \times$ studies : A. Group I normal retina consists of layers from outward to inward; RPE, PRL, ONL, OPL, INL, IPL, GCL, NFL, and ILM. A choroid layer (C) is seen adjacent to the RPE and definitive scleral cartilage (S) is seen adjacent to the choroid. B. Group II is the ten layers of the retina. Notice the OPL and the IPL exhibit reticular appearance. A layer of hyaline cartilage within the sclera (S) appears adjacent to the choroid (C). C. Group III disorganization with focal separation and vacuolated cells of the RPL, disorganized and vacuolated PRL (*). Notice multiple empty spaces (E) in the INL and an apparent decrease of the thickness of the ONL with disorganized cells. D. Group IV focal separation of the RPL (arrow), vacuolations (V) of the INL and marked empty areas (E). Notice disorganized OPL and IPL with apparent decreased thickness. GCL shows multiple areas of vacuolation $\left.{ }^{*}\right)$. Scleral (S) cartilage appears with dark pyknotic nuclei. Symbols of retinaal layers were explained in the main text.

The RPE formed of tall columnar cells with wide gaps due to rods and cones projecting in between, showing a vacuolated area. The PRL could be seen as the pale-looking, lightly stained elongated photoreceptor cells projecting towards the RPE producing vacuolated appearances. The ONL was formed of a band of cells with rounded nuclei. Moreover, the OPL appeared thin fibrous layer. The compact INL with predominantly rounded nuclei and a wide multilayered IPL layer formed of fibrous tissue. Underneath the IPL, the single-layered ganglion cells and glial cells ran parallel to IPL. The ganglion cells axons extended down and formed the NFL. The retina's inner limit was the thin ILM.

Group III treated with low concentration (2\%) showed a focal area of separation of the RPL and other sections with loss of the retinal pigment epithelium. The ONL showed few cells with deeply stained pyknotic nuclei. Multiple empty spaces in the INL with mild degenerated cells with pyknotic nuclei were seen. GCL showed multiple vacuolation areas around a few shrunken and irregular ganglion cells and some cells had deeply stained pyknotic nuclei. OPL and
IPL appeared nearly as the control group. A choroid layer was seen wide with increased fibrous tissue and dilated blood vessels sinusoids. At the scleral layer, marked degenerated chondrocytes with deeply stained pyknotic nuclei were observed (Figs. 8C and 9C).

Group IV treated with high concentration (5\%) showed an apparent marked reduction in the retinal thickness and marked disorganization of all layers. Some sections appeared with the area with loss of the retinal pigment epithelium of RPL. There was a focal separation of the retinal pigment epithelium in the RPL, which appeared with deeply acidophilic cytoplasm and deeply stained pyknotic nuclei. The photoreceptor cell layer exhibited marked loss of rods and cones, which appeared as empty spaces without cell processes. The nuclei of the INL and ONL are small and darkly stained pyknotic nuclei with widenining of intercellular spaces between the cells of the ONL. The GCL revealed pyknotic nuclei of ganglionic cells with some vacuolation. ILM appeared very thin and disrupted. Disorganized OPL and IPL are noticed with an apparent decrease in their thickness. The choriocapillaris layer had dilated congested blood 

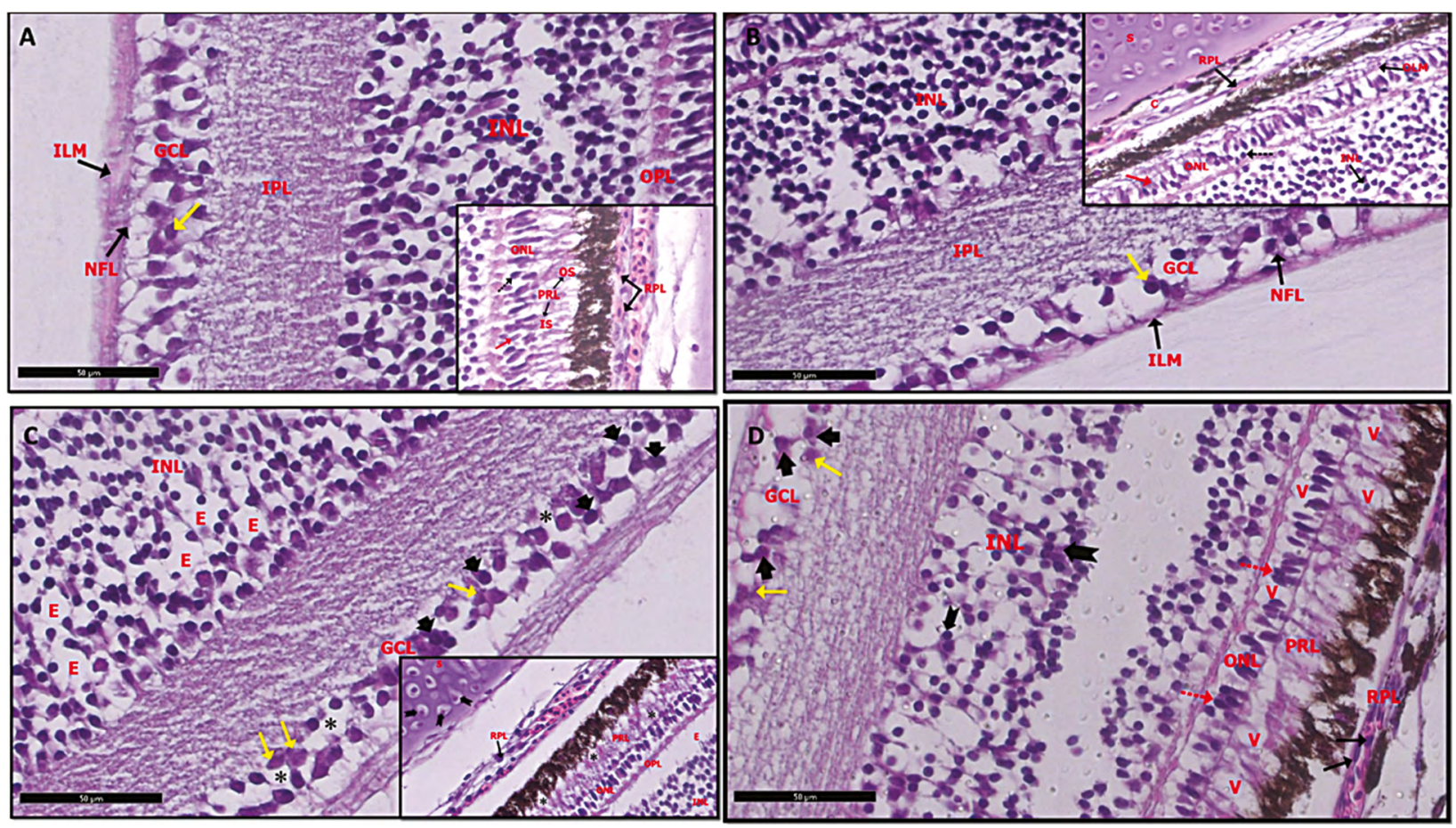

Figure 7. Higher magnification of the previous section at E9 at 40×: A. Group (I)IPL with the same reticular appearance of the OPL, but thicker. GCL is formed of one row of large rounded widely separated ganglion cells (yellow arrow) with large pale nuclei. INL appears with larger and paler nuclei with different shapes, sizes, and densities than those of the ONL. Inset: Retinal pigment epithelium appears as a single layer of small cuboidal cells that have pale, oval, basal nuclei and are filled with pigment granules $(\uparrow)$. The eosinophilic parallel fibrillary striation pattern of the PRL is composed of lightly stained outer segments (OS) and densely stained inner segments (IS) of the rods and cones. ONL consists of multiple regularly arranged rows of small dark nuclei of rod cells (dot arrow) and fewer larger and lighter nuclei of cone cells (red arrow). OPL exhibits a reticular appearance. Part of INL appears with larger and paler nuclei. B. Group II the ten layers of the retina with the same histological appearance as group I. C. Group III multiple empty spaces (E) in the INL. There is also multiple areas of vacuolation in the GCL (*) around a few shrunken and irregular ganglion cells (yellow arrow) and some cells had deeply stained nuclei pyknotic nuclei (arrowhead). Inset: Disorganization with focal separation and vacuolated cells of the RPL, disorganized and vacuolated PRL (*). OPL appears thinned and disrupted. Notice multiple empty spaces (E) in the INL and an apparent decrease of the thickness of the ONL with disorganized cells. Scleral cartilage cell nest appears with many apoptotic nuclei (bifid arrowhead). D. Group IV RPL with deep acidophilic and dark pyknotic nuclei ( $\uparrow$ ) of the retinal pigment epithelium. The diminished cell population of the ONL and INL with empty spaces between their cells and many pyknotic nuclei in the ONL (red dot arrow) and INL (bifid arrowhead). Notice disorganized PRL with apparent decreased thickness and multiple areas of vacuolation (V). GCL shows pyknotic nuclei of many ganglion cells (arrowhead) and there are also multiple areas of vacuolation around a few shrunken and irregular ganglion cells (yellow arrow) and some cells had deeply stained pyknotic nuclei (arrowhead). Symbols of retinaal layers were explained in the main text.

vessels with increased fibrous tissue. The scleral layer was seen with marked degenerated chondrocytes with deeply stained pyknotic nuclei (Figs. 8D and 9D).

\section{Discussion}

Studies published in the previous years to focus on the effects of inhaling e-liquid aerosols. Most of these studies aimed to study its effects on the heart, lung, brain, kidneys, liver, and male reproductive system. Each study differed from others in the way the researcher treats cells or tissues with e-liquid, components of e-liquid according to different con- centrations, flavor used, and other criteria. The issue of widespread use of e-cigarettes is neglected in the Kingdom of Saudi Arabia. Until recently, it turned out that no clinical reports or randomized trials related to the health effects of using e-cigarettes on the Saudi population have been announced [23].

This study was designed to evaluate the effect of e-cigarette flavoring agents (cinnamon flavor) in inducing apoptosis after the early and late stages of apoptosis in neural retinal of the chick embryo on the molecular (gene) level for proapoptotic $C A S P$-3, then correlate the gene expression finding with histological examination of the neural retinal tissue. 

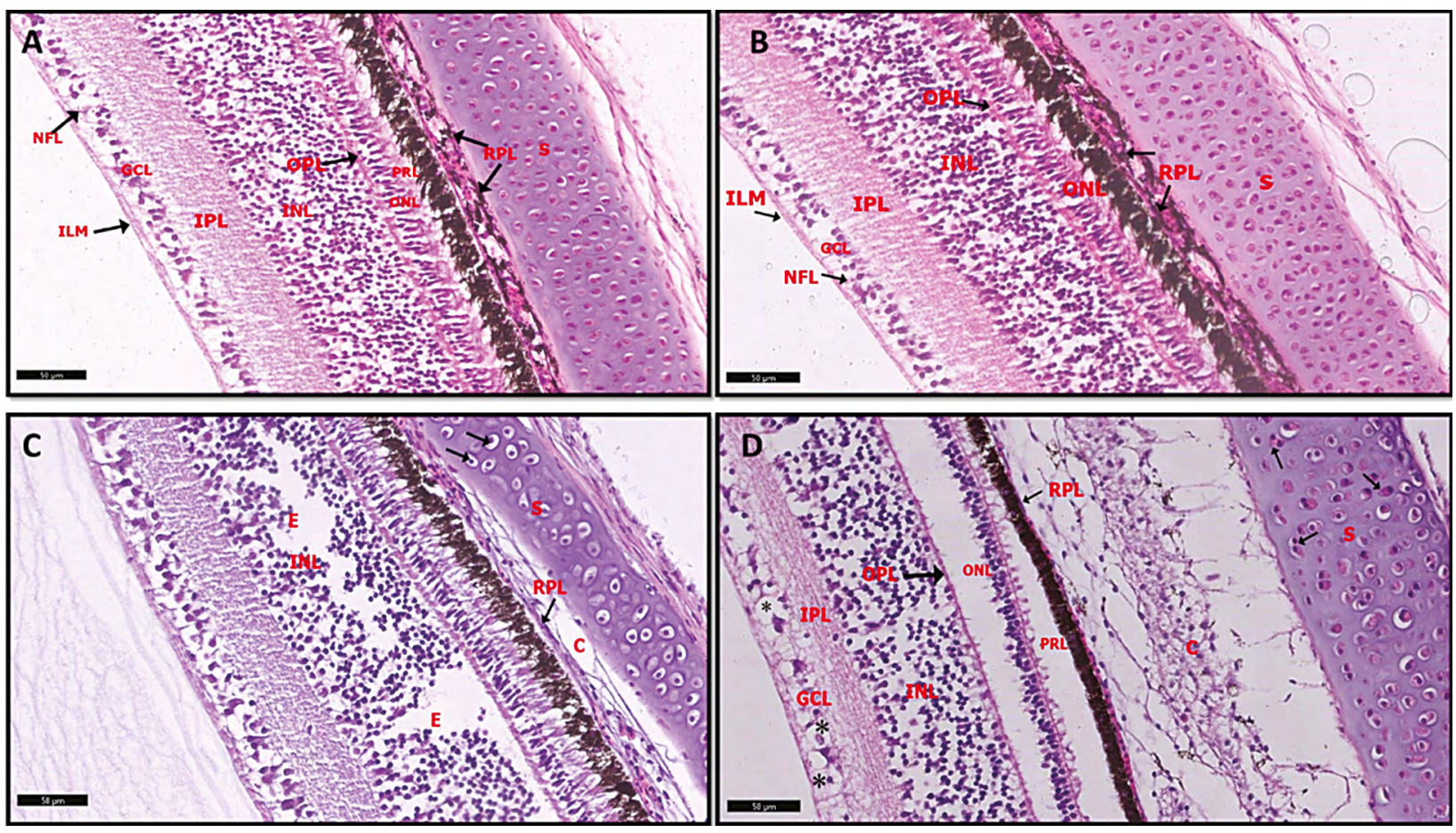

Figure 8. Photomicrographs of a section in the retina of at E17 at magnification $20 \times$ : A. Group I normal retina consists of layers from outward to inward; pigment epithelium $(\uparrow)$ with pigment granules, rods, and cones, a vague impression of OLM. A thin OPL, well-developed ONL and INL, IPL, GCL, NFL, and ILM. Notice the OPL and the IPL exhibit reticular appearance. A layer of cartilage within the sclera (S) is observed. B. Group II the ten layers of the retina as in group I. C. Group III area with loss of the retinal pigment epithelium of RPL. Notice multiple empty spaces in the INL. A choroid layer (C) is seen wide with increased fibrous tissue with dilated blood vessels sinusoids and the scleral layer (S) is seen with marked degenerated chondrocytes with deeply stained pyknotic nuclei $(\uparrow)$. D. Group IV area with loss of the retinal pigment epithelium of RPL. Notice multiple empty spaces in the INL. GCL shows multiple areas of vacuolation (*). A choroid layer (C) is seen wide with increased fibrous tissue with dilated blood sinusoids and the scleral layer $(\mathrm{S})$ is seen with marked degenerated cartilaginous sclera with deeply stained pyknotic nuclei $(\uparrow)$. Symbols of retinaal layers were explained in the main text.

Cinnamon flavor has been chosen in this scientific experiment, it contains toxic concentrations from the cinnamaldehyde that negatively affect the health of embryonic cells, it also contains other dangerous chemical compounds [24].

In the present study, $C A S P-3$ expression levels were significantly downregulated when exposed to the low and high dose of cinnamon flavor used in the e-liquids of the e-cigarette at E9 in comparison to control groups. These findings could be explained by the toxic effects of cinnamon flavor, which induced oxidative stress and apoptosis [26]. Meanwhile, at $\mathrm{E} 17$, the $C A S P$ - 3 expression level in the wild type of group was significantly lower than PBS group and no dark pyknotic nuclei were noticed in all layers of the retina. This came in agreement with Vecino et al. [20], who mentioned that the later wave of programmed cellular death in the developing chick retina occurs between E10 and E14; hence, E17 follows the late cell death. Additionally, Doonan et al. [27], mentioned that the cells of the immature retina are inherently different from adult retinal neurons in terms of the pro-apoptotic mediators they express. A host of pro-apoptotic proteins are expressed at high levels in the emerging retina and downregulated at postnatal days. These include downstream mediators such as CASP-3 and CASP-7. Although the cells appeared in an apoptotic state in all layers of the retina, the level of CASP-3 was downregulated. This could be explained by the occurrence of apoptosis through different factors other than CASP-3, most likely by an apoptosis-inducing factor (AIF), which is released from mitochondria in a caspase-dependent and a caspase-independent manner. AIF is another mitochondrial-associated protein. It is normally located in the intermembrane space of mitochondria and upon a proapoptotic signal AIF will be released from the mitochondria. Subsequently, AIF migrates to the nucleus, triggers DNA damage, and participates in the activation of caspase 9 in the cytoplasm. The alternative apoptotic pathway is the external pathway in which death receptors and 

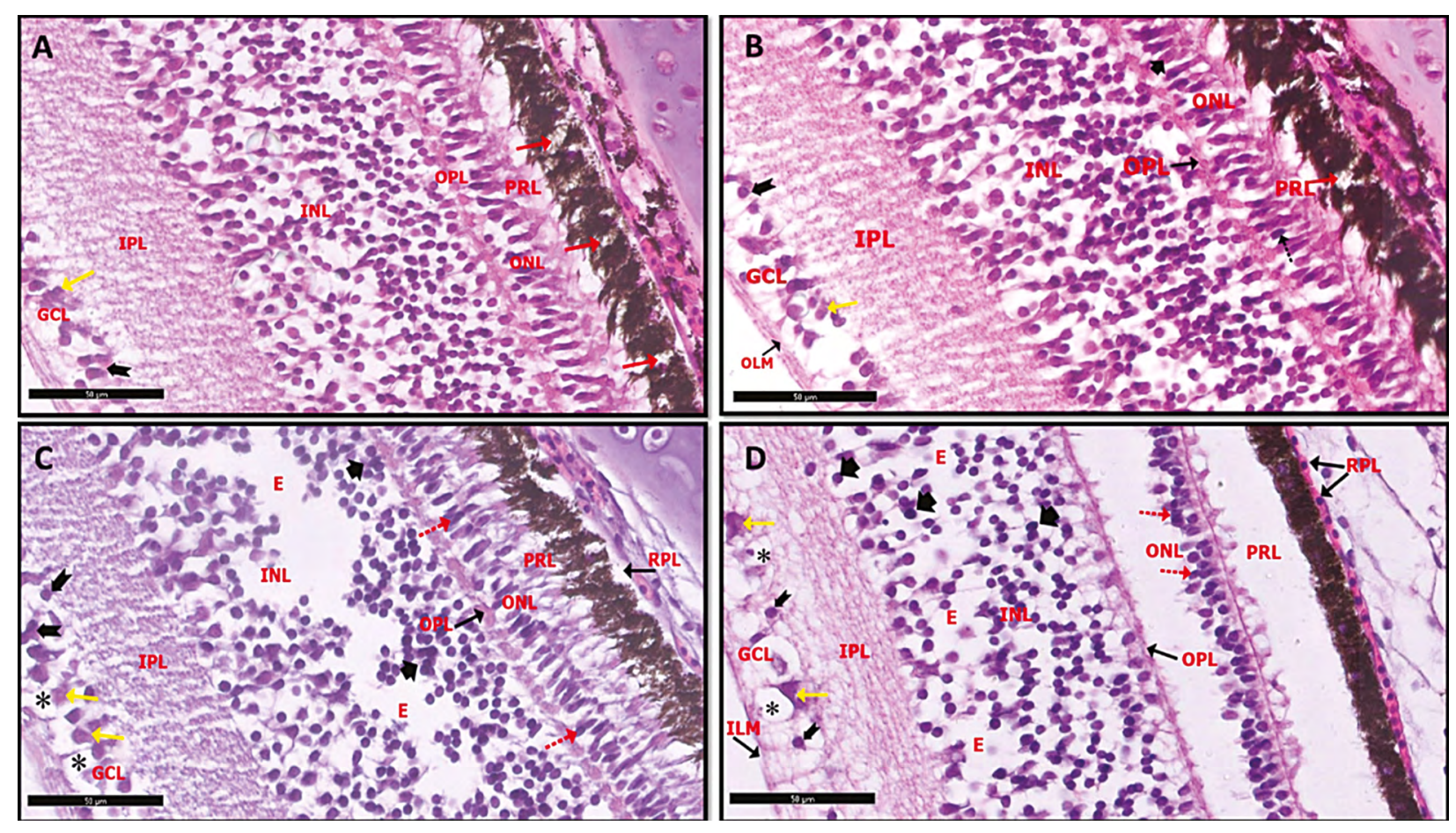

Figure 9. Higher magnification of the previous section at E17 at 40×: A. Group (I) IPL with the same reticular appearance of the OPL, but thicker and with obviously elongated photoreceptor cells in the PRL protruding in the pigment epithelium producing vacuolated appearances (red arrow). GCL is formed of one large rounded widely separated ganglion cells (bifid arrowhead) with large pale nuclei and few glial cells (yellow arrow). Moreover, INL appears with larger and paler nuclei with different shapes, sizes, and densities than those of the ONL. B. Group II the ten layers of the retina with the same histological appearance as group I. C. Group III focal area of separation of the RPL. The ONL shows few cells with deeply stained pyknotic nuclei (red dot arrow). Multiple empty spaces (E) in the INL with mild degenerated cells with pyknotic nuclei (arrowhead) are seen. GCL shows multiple areas of vacuolation $\left(^{*}\right)$ around a few shrunken and irregular ganglion cells (yellow arrow) and some cells had deeply stained pyknotic nuclei (bifid arrowhead). Notice OPL and IPL with appearing nearly as the control group. D. Group IV deeply acidophilic retinal pigment epithelium with darkly stained pyknotic nuclei of RPL. The ONL appears with marked thinning and deeply stained pyknotic nuclei (red dot arrow). Multiple empty spaces (E) in the INL with marked degenerated cells with pyknotic nuclei (arrowhead) are seen. GCL shows multiple areas of vacuolation (*) around a few shrunken and irregular ganglion cells (yellow arrow) and some cells had deeply stained pyknotic nuclei (bifid arrowhead). ILM appears very thin and disrupted. Notice disorganized OPL and IPL with apparent decreased thickness.

caspase 8 are the main players. Both internal and external apoptotic pathways activate caspase-activated DNase (CAD), thereby inducing specific DNA fragmentation and apoptotic cell death [28]. Additionally, Méndez-Armenta and his colleagues mentioned that increased ROS production impairs mitochondrial function, which consequently can lead to the release of pro-apoptotic molecules to the cytoplasm, mitochondrial swelling, and mitochondrial membrane rupture leading to the activation of different modes of cell death [28]. Chuang et al. [29] mentioned that recent evidence had suggested an intimate link between oxidative stress and mitochondrial dysfunction with the development of neuronal death.

In the present study, apoptotic cell death, also measured by histological observation, occurred in mostly all layers of the retina and the sclera, in which cells are characterized by deeply stained acidophilic cytoplasm and dark pyknotic nuclei. This cell death was not supposed to be observed at E17 and E9, no cell death occurs naturally. E9 and E17 embryonic stages were chosen because it is known to follow the early and late cell death wave in the chick developing retina, which lasts from E4 to E7 and E10 to E14, respectively [20].

In the current study, the retina exposed to an e-cigarette flavoring agent (cinnamon flavor) displays an apparent reduction in the retinal thickness and disorganization of all layers. These findings are aggravated on exposure to a high concentration of $5 \%$ of flavoring agent in E17. These observations are consistent with a study by Lee and his colleagues, who stated that exposure to cinnamon flavor agents in e-cigarette decreases endothelial cell viability and function, ele- 
vates the ROS levels, CASP-3 and CASP-7 activity, and activation of the oxidative stress-related pathways [30].

In the present study, exposure of RPE to low and high concentrations of e-cigarette flavoring agent (cinnamon flavor) showed separation, vacuolations, disorganization, and loss of the RPE in some areas in both E9 and E17. These findings could be explained by the toxic, oxidative stress, and inflammatory response produced by flavoring agents in the e-liquid of e-cigarettes [31, 32].

Moreover, some RPE cells revealed apoptotic cells characterized by deeply stained acidophilic cytoplasm and deeply stained pyknotic nuclei when exposed to high concentrations in E17. This could be explained by a decrease in the cell viability and augmentation of Interleukin-6 (IL-6) and Interleukin-8 (IL-8) release, cellular stress, and morphological changes caused by cinnamon flavor [31].

In the present study, exposure to low and high concentrations of cinnamon flavor at E9 led to the occurrence of multiple empty spaces in the INL and ONL. The GCL display focal areas of multiple vacuolations. Apoptosis was evident in many cells in the INL, GCL, and scleral cartilage cells, especially when exposed to a high concentration. These findings agree with Behar et al. [24], who demonstrated that cinnamaldehyde-containing refill fluids and aerosols are cytotoxic, genotoxic, and affect cell processes and survival. The flavor agents result in oxidative stress with an elevated level of ROS production and excessive IL-8 secretion leading to cell cytotoxicity and DNA damage [33].

In the present study, exposure to low and high concentrations of cinnamon flavor at E17 resulted in a decrease in the number and the density of the cells in the INL, ONL, and GCL. Apoptotic cells appeared in all layers and the scleral layer with marked degenerated chondrocytes, exaggerated with high concentration. These findings could be explained by the fact that e-cigarette use has been found to trigger cell cytotoxicity and genotoxicity. Vapor exposure is also related to oxidative stress, with a strong connection between vapor exposure and the overproduction of pro-inflammatory agents [8]. Studies revealed that e-cigarette aerosols induce a dose-dependent and nicotine-independent increase of DNA damage. Exposure to vapor is characterized by elevated ROS levels, the most abundant oxidative stress-induced DNA lesions [34].

In the current study, disorganization of the OPL and IPL was observed with a widening of the spaces between their fibers and an apparent decrease in their thickness. Muthumalage et al. [35] demonstrated that exposure to e-liquid flavoring agents cinnamaldehyde caused an inflammatory response in monocytes and increased ROS production, which may cause pulmonary toxicity and tissue damage. Additionally, Clapp et al. [36] mentioned that vapors impair mitochondrial respiration and glycolysis, reduce intracellular ATP levels, and induce significant phenotypical changes in the human bronchial epithelial cells. The retina has multiple neurons which use a relatively large amount of $\mathrm{O}_{2}$ in mitochondria to generate ATP needed to maintain the vital process in the cell. Adequate energy supply by mitochondria is essential for neuronal excitability and neuronal survival [37]. This fact might be the reason for the higher susceptibility of neuronal cells to the aerosol condensate agent in this study.

In the current study, toxic effects resulting from exposure to cinnamaldehyde as an e-liquid flavoring agent caused toxic effects on all retina layers compared to the control tissue sample. These toxic effects increase with high dose exposure, probably triggering an inflammatory response and IL-8 secretion mediated by ROS production. ROS are highly reactive chemicals possessing unpaired electrons in the outer shell. ROS are considered essential for regulating normal physiological functions involved in development such as cell cycle progression and proliferation, differentiation, migration, and cell death at low to modest doses. Increased oxidative stress generally describes a condition in which cellular antioxidant defenses cannot suppress the ROS that can result in cellular injury, DNA damage, protein oxidation and disruption of the cell functions, and/or inducing cell death of the CNS neurons.

Moreover, ROS are known to be involved in the apoptosis mechanism for neuronal cell death [28]. Previous studies on the assessment of the ROS generated by e-cigarettes using different approaches reported that ROS could initiate oxidative stress followed by other pathological processes. e-Cigarette vapor has been found to contain $7 \times 10^{11}$ free radicals per puff. ROS production has been found to be provoked by the inhalation of toxic agents, stimulating inflammatory signaling pathways. One such stimulant of ROS release is exposure to the vapor from e-cigarettes $[38,39]$.

\section{Conclusions}

There is a noticeable increase in e-cigarette use worldwide, but few studies investigated flavors agents and their effects. These results concern that flavored e-liquids may contain dangerous chemicals and reveal a potential risk to e-cigarette users when they inhale vapors. More research will be needed to investigate these flavors and their products further when heated 
and aerosolized. Besides, it is suggested that there should be more studies to evaluate the cytotoxicity and genotoxicity of aerosols. More clinical studies are required to evaluate the effects of common flavors among e-liquid users on the neural retina. Studies may benefit community members to increase awareness of the risks of using e-cigarettes. Moreover, it is necessary to limit the marketing of e-cigarettes and their products.

\section{Acknowledgments}

We thank King Fahd Medical Research Center (KFMRC), Jeddah, for facilitating conducting of this research. Ms. Manal Shaabad from the Center of Excellence in Genomic Medicine Research for her assistance and guidance with rt-qPCR and Ms. Kholod Albriky for her help with preparing histological samples. The work is a requirement for a postgraduate degree offered by the Department of Biological Sciences, Faculty of Science, King Abdulaziz University at Jeddah, which facilitated the progress of these experiments.

\section{Funding}

This research received no external funding.

\section{Institutional review board statement}

The study was designed with correspondence to the codes of the guidelines for Ethical Conduct in the Care and Use of Animals; experimental conduct and handling were authorized via the Animal Ethics division within the Ethics Committee of Biomedical Research-Faculty of medicine at King Abdul Aziz University, ethical approval number (reference \#59019). The experiment was executed in consensus with the guidelines of dealing with experimental animals that are followed in KFMRC, KAU, Jeddah, Saudi Arabia, which are in accordance with the Canadian Council for animal safety and health care.

\section{Informed consent statement}

Not applicable.

\section{Data availability statement}

Data are contained within the article.

\section{Conflicts of interest}

The authors declare no conflict of interest.

\section{References}

1. Nguyen T. Electronic Cigarettes: Neurological Effects on Murine Offspring and the Response of Neuronal Cells. 2020.

2. Dutra LM, Grana R, Glantz SA. Philip Morris research on precursors to the modern e-cigarette since 1990. Tob Control. 2017; 26(e2): e97-e9e105, doi: 10.1136/tobaccocontrol-2016-053406, indexed in Pubmed: 27852893.

3. Leigh NJ, Lawton RI, Hershberger PA, et al. Flavourings significantly affect inhalation toxicity of aerosol generated from electronic nicotine delivery systems (ENDS). Tob Control. 2016; 25(Suppl 2): ii81-ii87, doi: 10.1136/tobaccocontrol-2016-053205, indexed in Pubmed: 27633767.

4. Barrington-Trimis JL, Samet JM, McConnell R. Flavorings in electronic cigarettes: an unrecognized respiratory health hazard? JAMA. 2014; 312(23): 2493-2494, doi: 10.1001/ jama.2014.14830, indexed in Pubmed: 25383564.

5. Kaur G, Muthumalage T, Rahman I. Mechanisms of toxicity and biomarkers of flavoring and flavor enhancing chemicals in emerging tobacco and non-tobacco products. Toxicol Lett. 2018; 288: 143-155, doi: 10.1016/j.toxlet.2018.02.025, indexed in Pubmed: 29481849.

6. Krüsemann EJZ, Boesveldt S, de Graaf K, et al. An E-Liquid Flavor Wheel: A shared vocabulary based on systematically reviewing E-liquid flavor classifications in literature. Nicotine Tob Res. 2019; 21(10): 1310-1319, doi: 10.1093/ntr/nty101, indexed in Pubmed: 29788484.

7. Clapp PW, Pawlak EA, Lackey JT, et al. Flavored e-cigarette liquids and cinnamaldehyde impair respiratory innate immune cell function. Am J Physiol Lung Cell Mol Physiol. 2017; 313(2): L278-L292, doi: 10.1152/ajplung.00452.2016, indexed in Pubmed: 28495856.

8. Merecz-Sadowska A, Sitarek P, Zielinska-Blizniewska H, et al. A summary of in vitro and in vivo studies evaluating the impact of E-cigarette exposure on living organisms and the environment. Int J Mol Sci. 2020; 21(2), doi: 10.3390/ ijms21020652, indexed in Pubmed: 31963832.

9. Theron AJ, Feldman C, Richards GA, et al. Electronic cigarettes: where to from here? J Thorac Dis. 2019; 11(12): 5572-5585, doi: 10.21037/jtd.2019.11.82, indexed in Pubmed: 32030277 .

10. Bitzer ZT, Goel R, Reilly SM, et al. Effect of flavoring chemicals on free radical formation in electronic cigarette aerosols. Free Radic Biol Med. 2018; 120: 72-79, doi: 10.1016/j. freeradbiomed.2018.03.020, indexed in Pubmed: 29548792.

11. Sussan TE, Gajghate S, Thimmulappa RK, et al. Exposure to electronic cigarettes impairs pulmonary anti-bacterial and anti-viral defenses in a mouse model, PLoS One. 2015; 10: e0116861, doi: 10.1371/journal.pone.0116861, indexed in Pubmed: 25651083.

12. Scheffler S, Dieken H, Krischenowski O, et al. Evaluation of E-cigarette liquid vapor and mainstream cigarette smoke after direct exposure of primary human bronchial epithelial cells. Int J Environ Res Public Health. 2015; 12(4): 3915-3925, doi: 10.3390/ijerph120403915, indexed in Pubmed: 25856554.

13. D'amelio M, Cavallucci V, Cecconi F. Neuronal caspase-3 signaling: not only cell death. Cell Death Differ. 2010; 17(7): 1104-1114, doi: 10.1038/cdd.2009.180, indexed in Pubmed: 19960023.

14. Allen JG, Flanigan SS, LeBlanc M, et al. Flavoring Chemicals in E-Cigarettes: Diacetyl, 2,3-Pentanedione, and Acetoin in a Sample of 51 Products, Including Fruit-, Candy-, and Cocktail-Flavored E-Cigarettes. Environ Health Perspect. 2016; 124(6): 733-739, doi: 10.1289/ehp.1510185, indexed in Pubmed: 26642857. 
15. Faden A, Yakovlev A. Caspase-dependent apoptotic pathways in CNS injury. Mol Neurobiol. 2001; 24(1-3): 131-144, doi: 10.1385/mn:24:1-3:131.

16. Carnevali S, Petruzzelli S, Longoni B, et al. Cigarette smoke extract induces oxidative stress and apoptosis in human lung fibroblasts. Am J Physiol Lung Cell Mol Physiol. 2003; 284(6): L955-L963, doi: 10.1152/ajplung.00466.2001, indexed in Pubmed: 12547733.

17. Goel R, Durand E, Trushin N, et al. Highly reactive free radicals in electronic cigarette aerosols. Chem Res Toxicol. 2015; 28(9): 1675-1677, doi: 10.1021/acs.chemrestox.5b00220, indexed in Pubmed: 26244921.

18. Trachsel-Moncho L, Benlloch-Navarro S, Fernández-Carbonell Á, et al. Oxidative stress and autophagy-related changes during retinal degeneration and development. Cell Death \& Disease. 2018; 9(8), doi: 10.1038/s41419-018-0855-8, indexed in Pubmed: 30042417.

19. Wisely CE, Sayed JA, Tamez H, et al. The chick eye in vision research: An excellent model for the study of ocular disease. Prog Retin Eye Res. 2017; 61: 72-97, doi: 10.1016/j.preteyeres.2017.06.004, indexed in Pubmed: 28668352.

20. Vecino E, Hernández M, García M. Cell death in the developing vertebrate retina. Int J Dev Biol. 2004; 48(8-9): 965-974, doi: 10.1387/ijdb.041891ev, indexed in Pubmed: 15558487.

21. Olmedo P, Navas-Acien A, Hess C, et al. A direct method for e-cigarette aerosol sample collection. Environ Res. 2016; 149: 151-156, doi: 10.1016/j.envres.2016.05.008, indexed in Pubmed: 27200479.

22. J.D. Bancroft, Gamble M. Theory and practice of histological techniques, 7th ed, Elsevier health sciences, USA: Churchill Livingston; 2008.

23. Khanagar SB, Siddeeqh S, Khinda V, et al. Impact of electronic cigarette smoking on the Saudi population through the analysis of literature: A systematic review. J Oral Maxillofac Pathol. 2019; 23(3): 473, doi: 10.4103/jomfp.JOMFP_141_19, indexed in Pubmed: 31942135.

24. Behar RZ, Luo W, Lin SC, et al. Distribution, quantification and toxicity of cinnamaldehyde in electronic cigarette refill fluids and aerosols. Tob Control. 2016; 25(Suppl 2): ii94-ii9ii102, doi: 10.1136/tobaccocontrol-2016-053224, indexed in Pubmed: 27633763.

25. Fleige S, Pfaffl MW. RNA integrity and the effect on the real-time qRT-PCR performance. Mol Aspects Med. 2006; 27(2-3): 126-139, doi: 10.1016/j.mam.2005.12.003, indexed in Pubmed: 16469371.

26. Tommasi S, Bates S, Behar R, et al. Limited mutagenicity of electronic cigarettes in mouse or human cells in vitro. Lung Cancer. 2017; 112: 41-46, doi: 10.1016/j.lungcan.2017.07.035, indexed in Pubmed: 29191599.

27. Doonan F, Groeger G, Cotter TG. Preventing retinal apoptosis--is there a common therapeutic theme? Exp Cell Res. 2012; 318(11): 1278-1284, doi: 10.1016/j.yexcr.2012.02.003, indexed in Pubmed: 22366479.

28. Méndez-Armenta M, Nava-Ruíz C, Juárez-Rebollar D, et al. Oxidative stress associated with neuronal apoptosis in experimental models of epilepsy. Oxid Med Cell Longev. 2014; 2014: 293689, doi: 10.1155/2014/293689, indexed in Pubmed: 25614776.

29. Chuang Y.-C. Mitochondrial dysfunction and oxidative stress in seizure-induced neuronal cell death. Acta Neurol Taiwan. 2010; 19(1): 3-15, indexed in Pubmed: 20711885.

30. Lee WH, Ong SG, Zhou Y, et al. Modeling cardiovascular risks of E-cigarettes with human-induced pluripotent stem cell-derived endothelial cells. J Am Coll Cardiol. 2019; 73(21): 2722-2737, doi: 10.1016/j.jacc.2019.03.476, indexed in Pubmed: 31146818.

31. Behar RZ, Davis B, Wang Y, et al. Identification of toxicants in cinnamon-flavored electronic cigarette refill fluids. Toxicol In Vitro. 2014; 28(2): 198-208, doi: 10.1016/j.tiv.2013.10.006, indexed in Pubmed: 24516877.

32. Lerner CA, Sundar IK, Yao H et al. Vapors produced by electronic cigarettes and e-juices with flavorings induce toxicity, oxidative stress, and inflammatory response in lung epithelial cells and in mouse lung. PLoS One. 2015; 10: e0116732.

33. Cadet J, Wagner JR. DNA base damage by reactive oxygen species, oxidizing agents, and UV radiation. Cold Spring Harb Perspect Biol. 2013; 5(2), doi: 10.1101/cshperspect.a012559, indexed in Pubmed: 23378590.

34. Mangal D, Vudathala D, Park JH, et al. Analysis of 7,8-dihydro-8-oxo-2'-deoxyguanosine in cellular DNA during oxidative stress. Chem Res Toxicol. 2009; 22(5): 788-797, doi: 10.1021/tx800343c, indexed in Pubmed: 19309085.

35. Muthumalage T, Prinz M, Ansah KO, et al. Inflammatory and oxidative responses induced by exposure to commonly used e-cigarette flavoring chemicals and flavored e-liquids without nicotine. Front Physiol. 2017; 8: 1130, doi: 10.3389/ fphys.2017.01130, indexed in Pubmed: 29375399.

36. Clapp PW, Lavrich KS, van Heusden CA, et al. Cinnamaldehyde in flavored e-cigarette liquids temporarily suppresses bronchial epithelial cell ciliary motility by dysregulation of mitochondrial function. Am J Physiol Lung Cell Mol Physiol. 2019; 316(3): L470-L486, doi: 10.1152/ajplung.00304.2018, indexed in Pubmed: 30604630.

37. Chen S-D, Yang D-I, Lin T-K, et al. Chuang, Roles of oxidative stress, apoptosis, PGC- $1 \alpha$ and mitochondrial biogenesis in cerebral ischemia. Int. J Mol Sci. 2011; 12(10): 7199-7215, doi: 10.3390/ijms12107199, indexed in Pubmed: 22072942.

38. Anderson C, Majeste A, Hanus J, et al. E-cigarette aerosol exposure induces reactive oxygen species, dna damage, and cell death in vascular endothelial cells. Toxicol Sci. 2016; 154(2): 332-340, doi: 10.1093/toxsci/kfw166, indexed in Pubmed: 27613717 .

39. Zhao J, Zhang Y, Sisler JD, et al. Assessment of reactive oxygen species generated by electronic cigarettes using acellular and cellular approaches. J Hazard Mater. 2018; 344: 549-557, doi: 10.1016/j.jhazmat.2017.10.057, indexed in Pubmed: 29102637.

Submitted: 23 July, 2021

Accepted after reviews: 29 November, 2021 Available as AoP: 9 December, 2021 